\title{
Is the library part of the picture? Asking honors undergrads to describe their research processes
}

ibrarians at Duke University, like their —colleagues across the country, are increasingly interested in knowing more about their users and the ways that they use-or opt not to use-library spaces, resources, and services. The hope, of course, is that understanding the unique needs and interests of distinct patron populations will enable us to improve their experiences in the libraries.

Undergraduate researchers, students engaging in graduate-level research often culminating in a thesis or major project, comprise one such user group that a number of libraries are considering in their outreach endeavors, whether it be by recognizing outstanding research with library prizes, coordinating "Personal Librarian" programs, providing coursespecific instruction to students enrolled in honors research seminars, scheduling research consultations required by students' departments, or designating building space specifically for undergraduates engaging in high-level research.

The connection between librarians/ library collections and undergraduate researchers is an obvious one, and the increasing level of importance that universities are placing on undergraduate research underscores the need for librarians to consider the interests of these particular users. ${ }^{1}$

This attention to undergraduate research is certainly evident at Duke University. In 2005, the administration set a goal to double the number of undergraduates who complete honors theses or projects and thereby "graduate with distinction." And in May 2010, Duke achieved its goal: 26 percent of the 2010 graduating class completed honors theses or projects (just 12 percent of the 2005 graduating class earned distinction), and the number continues to grow in nearly every department on campus. ${ }^{2}$ The university has developed extensive support mechanisms for these students-honors seminars, a dean and office to oversee the distinction program, an annual symposium - and Duke's librarians have worked with key stakeholders on campus to ensure that they are an integral part of this infrastructure. ${ }^{3}$

While the libraries' specialized support services for honors researchers have been well received by students, faculty and administration, we librarians did not feel that we had a clear picture of the research process from undergraduates' points of view. In an attempt to increase our understanding, we designed a user study that documented and analyzed how students navigate their theses-from formulating research questions to writing their final products.

Before beginning the study, I met with the Directors of Undergraduate Studies (DUSs) in five departments: biology, Eng-

Emily Daly is coordinator of upper level instruction, librarian for education at Duke University's Perkins Library, e-mail: emily.daly@duke.edu

(c) 2011 Emily Daly 
lish, history, public policy, and program II, a self-designed program of study. DUSs were supportive and provided permission to recruit students who intended to graduate with distinction from their departments. I recruited nine volunteers representing four disciplinary areas: biology (two students); history (two students); public policy (three students); and program II (two students). Unfortunately, I was unable to recruit students from the English department.

Each of the nine students was interviewed three times over the course of the fall 2009 and spring 2010 semesters. ${ }^{4}$ One interview was conducted at the beginning of students' research, one midway through their thesis process, and one after their theses were completed and submitted. Interviews ranged from 15 to 40 minutes, and I both took notes during the interviews and audio recorded them for later reference. I then systematically reviewed notes from all interviews for common themes and trends.

All nine participants completed the study (i.e., they answered all three sets of questions), and all nine submitted theses to their departments, thereby earning graduation with distinction. One student changed advisors and departments midway through the process and essentially started and completed his thesis in one semester; otherwise, students' research processes spanned at least two academic semesters.

These nine students represent 2.5 percent of the 363 students who graduated with distinction in May 2010 and .6 percent of their graduating class, which totaled 1,396 students. Five of the nine graduated with "high distinction" (one student) or "highest distinction" (four students), an honor conferred by individual departments on the basis of students' theses. Of the four departments, biology graduated the most students with distinction (59), while program II graduated the fewest (seven). History and public policy had 22 and 21 students graduate with distinction, respectively.

\section{Findings: Role of Duke University Libraries in honors researchers' work}

All nine students expressed appreciation for library services tailored for honors researchers. One student said, "I thought the library would just keep doing what the library does [when I started my thesis], but you've gone above and beyond." All nine students were aware of at least some of the specialized services offered by the library (e.g., study carrels, lockers, group study room), but they took advantage of them to varying degrees.

Two students said that the library needs more lockers, and other students noted that they tried to use the group study room designated for honors researchers but found it to be very crowded. Three students said they wished they had used services such as the lockers or study carrels but forgot they were available or simply never "got around to using them."

Students used a variety of methods for organizing their research, including Excel; a physical binder, notebook, or file system; sticky notes to tag portions of books and notes; an electronic file system with Word documents and electronic folders or EndNote; and an online file system like Papers, Zotero, or RefWorks. Three students used citation software to format their citations (two used EndNote, one began using RefWorks and then switched to Zotero) and other students either started to use a tool and then abandoned it due to its complexity or decided from the start to format citations manually.

When asked what role the libraries played in their research and at what point the library was most critical to their work, six stated that it was most crucial for locating print and electronic resources both locally and through interlibrary loan. Four students representing three departments relied most heavily on the library as a physical space (four students did the bulk of their work in their apartments or dorm rooms, and one student used both the 
library and other spaces to complete her thesis). Overall, nine of the 19 human and physical resources deemed "critical" to the success of students' research were related to the libraries-students mentioned subject librarians, data services staff, ILL, and the libraries' chat/IM service, among others.

With that said, four students indicated that the libraries could do a better job of marketing their services and clarifying the role of the subject librarian in supporting their work. Study participants believe that students (including themselves) are generally not familiar with the research consultation service.

Two of nine study participants met individually with a subject librarian to discuss their research, and one e-mailed a subject librarian for search strategies and resource recommendations. It is worth noting that all three of these students received courseintegrated library instruction in conjunction with the honors seminar required by their departments, and all three graduated with "highest distinction," the highest honor conferred by the university for students' research.

Another student remarked that she "could have taken advantage of librarians' services but just didn't." She said she "would have enjoyed e-mailing back and forth with a librarian" in her field but was unclear of the role of her subject librarian in this process (note that she was also part of an honors seminar that included library instruction). One participant indicated that students "may need a push" to schedule a research consultation, suggesting that requiring honors researchers to meet with a librarian was worth exploring. She believes that "no student would have a problem with it, they just don't know it exists."

Study participants said that it makes most sense to incorporate research instruction and information about specialized services the libraries provide into honors seminars, which are offered by some departments but not all. One student believes that office hours designated for honors researchers would also be helpful. She believes other students would like to have the option of meeting with a subject specialist or data services librarian during these hours.

Two students (both in program II) believed that they did not need the libraries for their research given the nature of their projects. Another student (one who graduated with "highest distinction") said that he appreciates everything the library does but did not feel that librarians could have "added anything to his research" because it is just so "incredibly specific"; instead, he "asked his advisor or did the search [him]self."

Over the course of interviewing these nine students, I found that many were unaware of the full extent of library services and resources available to them. For instance, one student did not know that he could access library resources from off campus and rarely used the libraries homepage to access subscription resources. Two others were not aware that they could request materials from other institutions until we met (note that one of these students was part of an honors seminar that incorporated a library instruction session, and the other graduated not only with distinction but "high distinction"). Many incorrectly named library resources and services but were able to use them to meet their needs.

Overall, these nine honors researchers were confident in their abilities to complete high level research (none mentioned "using the library" or "conducting research" when asked, "What do you think will be the most difficult part of the whole process for you?" in their first interviews or "What was the most difficult aspect of your project?" in their last interviews), and all successfully completed theses and graduated with distinction.

Several students did, however, demonstrate gaps in their understanding of library services and the most efficient ways to access and evaluate library resources over 
the course of their interviews, confirming librarians' suspicions that we need to increase support for upper-level courses so that honors researchers are better prepared to conduct thesis research. These interviews also demonstrated the need to continue marketing services the libraries provide for honors researchers.

\section{Limitations and benefits of study}

The primary limitation of this study is the small sample size-themes identified from interviews with these nine students could be verified through a broader investigation involving other departments and larger numbers of undergraduate researchers. Also, while multiple librarians developed the study questions, I conducted all study interviews. While this helped ensure consistency among interviews, it may have lead to interviewer bias. Finally, the study participants were aware that I am a librarian at Duke, so although the students appeared to be candid and were encouraged to be critical, their answers may have been influenced by their perceptions of what I wanted to hear. Because students were interviewed while they were conducting their research, their participation in the study may have heightened their awareness of library resources and services. Followup research might include an assessment of the effectiveness of new library services for honors researchers and incorporate data from faculty advisors, honors seminar instructors and university administration to understand more fully the experiences of these students.

The benefits of this type of study are innumerable. Meeting with students three times over the course of the academic year enabled me to get to know them and see their research styles, questions, and processes emerge, evolve, and mature. I was also able to introduce library services and resources at their points of need (I was, however, careful to remain as objective as possible while they were answering interview questions. I answered their research questions at the conclusion of each interview). I believe that the casual, one-on-one interview setting was optimal for students to provide both positive and negative feedback about the libraries. It was also extremely worthwhile to interview students in a variety of disciplines, working on projects ranging from scientific discovery to a novella. Students also expressed that they benefitted from the opportunity to reflect on their research processes, and they seemed to appreciate the interest that I took in their research habits and needs.

\section{Final thoughts}

Researchers' habits are as individualized and unique as the questions that drive their theses, while we may draw some conclusions about best practices for supporting these undergraduates, we cannot draw clear lines based only on their disciplines, genders, or ages (i.e., "Science students don't go to the library to work, they do all of their work in the lab" or "This generation of students doesn't use notecards or paper and pen for taking notes or drafting their papers, they do everything online").

In fact, this is precisely what made this study so interesting - it also happens to make our jobs as librarians particularly challenging. We offer a suite of services based on our assumptions and in hopes of attending to the needs of as many students as possible, but oftentimes the best way to get to know our users and their unique perspectives is simply to ask.

\section{Notes}

1. A. Stamatoplos (2009), "The role of academic libraries in mentored undergraduate research: A model of engagement in the academic community," College $\varepsilon$ Research Libraries, 70(3), 235-249.

2. Trinity College of Arts \& Sciences, Duke University (2009), "Graduation with Distinction," retrieved from http://trinity.duke. edu/academic-requirements?p=graduationwith-distinction.

(continued on page 419) 
the digitized manuscripts PDF, a wonderful feature that is becoming more common. Moreover, no watermark is attached to the scans, making for a pristine personal copy for those interested. Access: http://art.thewalters. org/viewgallery.aspx?id=1254.

Finally, one should also peruse the Poetry and Prayer virtual exhibition. This exhibition highlights some of the different aspects of a Muslim's life from prayer, recitation, and calligraphy to poetry as well as having digitized many beautiful copies of the Quran. Access: http://poetryprayer.thewalters.org/books/.

\section{Associations and miscellanea}

- Archivalia. Archivalia is a Germanlanguage blog that disseminates knowledge on and about (European) print culture and a variety of different digital projects. Although not exclusive to Islamic/Arabic/Persian manuscript studies, it remains an important Web site for the plethora of ongoing digital projects. Access: http://archiv.twoday.net/.

\section{- Comparative Oriental Manuscript} Studies (Comst). The program, scheduled for the years 2009-14, aims at facilitating crosscultural academic dialogue and active exchange in the field of Oriental manuscript studies with a focus on the Mediterranean and North African cultural areas. So far no such exchange has been conducted systematically on a European level. Standards in all subfields of manuscript studies differ from one study area to another and from one national scholarly tradition to another. Oriental studies are considerably behind Occidental manuscript studies, where, for example, Greek and Latin philology have reached a high standard. Access: http://www1.unihamburg.de/COMST/

- E-Corpus. e-corpus is a collective digital library that catalogs and disseminates numerous documents: manuscripts, archives, books, journals, prints, audio recordings,
3. Duke University Libraries (2010), Check out what the library offers students writing honors theses, retrieved from http://library. video, etc. This diverse platform presents cultural diversity worldwide, specifically in the Euro-Mediterranean region. e-corpus proposes a variety of themes and a large quantity of digital documents presented by numerous organizations and countries. Based on cutting-edge technologies, e-corpus offers a simple and direct public access to a rich collection of resources. Access: http:// www.e-corpus.org/.

- Islamic Calligraphy Qalam: An Introduction to Arabic, Ottoman and Persian Calligraphy. This wonderful Web site provides the visitor with an immense amount of material in a concise and precise manner. It provides introductory videos on the tools and utensils of this beautiful trade, including how to properly configure the nib of a calligrapher's qalam (calamus), often a reed pen. Furthermore, the Web site provides updates on events and newly digitized Islamic materials from around the world. It is an indispensable resource for both the practitioner and the novice. Access: http://calligraphyqalam. com/index.html.

- The Islamic Manuscripts Association (TIMA). TIMA remains a premiere source for information concerning all aspects of Islamic manuscripts. Their newsletter is published monthly and contains important information on grants, workshops, digital projects, and general information related to the study of Islamic manuscripts. One is also able to search or browse the directory of members, which can be a nice way of getting to know the community. Access: http://www.islamicmanuscript.org/

In conclusion, the digitization of manuscripts with the advanced technology available is allowing scholars in this field more access than ever before.

\section{Note}

1. Book of Ecclesiastics, 12:12. n

duke.edu/research/undergraduate/index.html.

4. Interview questions are available online at http://library.duke.edu/services/instruction/honors-researchers-study.html $\boldsymbol{n}$ 